\title{
On the shakedown analysis of welded pipes
}

\author{
Tianbai Li, Haofeng Chen*, Weihang Chen and James Ure \\ Department of Mechanical Engineering, University of Strathclyde, Glasgow G1 1XJ, UK \\ *E-mail address: haofeng.chen@strath.ac.uk
}

\begin{abstract}
This paper presents the shakedown analysis of welded pipes subjected to a constant internal pressure and a varying thermal load. The Linear Matching Method (LMM) is applied to investigate the upper and lower bound shakedown limits of the pipes. Individual effects of i) geometry of weld metal, ii) ratio of inner radius to wall thickness and iii) all material properties of Weld Metal (WM), Heat Affected Zone (HAZ) and Parent Material (PM) on shakedown limits are investigated. The ranges of these variables are chosen to cover the majority of common pipe configurations. Corresponding individual influence functions on the shakedown limits are generated. These are then combined to allow the creation of a safety shakedown envelope, which can be used for the design of any welded pipes within the specified ranges. The effect of temperature dependent yield stress (in PM, HAZ and $\mathrm{WM}$ ) on these shakedown limits is also investigated.
\end{abstract}

Keywords: shakedown; reverse plasticity limit; ratchet limit; limit load; welded pipe

\section{Introduction}

The circumferential butt welded pipes are widely used in many industries and usually subjected to complex varying thermal and mechanical loads [1]. Under such loads, the pipes may fail either from the accumulated plastic deformations during the increasing load cycles or from the reverse plastic deformations. The former is known as ratchetting or incremental plasticity, which leads structures to incremental collapse; the latter is named reverse plasticity or alternating plasticity, which gives rise to a local low cycle fatigue. Plastic strain generated in a component which does not lead to either of these two mechanisms is referred to as shakedown, and this concept is widely used in the design of pressure vessels and piping systems.

Shakedown analysis of loaded structures has been investigated by many researchers in past decades [2-23]. The complexity of shakedown means that analytical solutions are rare, and thus incremental 
Finite Element Analysis (FEA) is widely used. Incremental FEA can only show if elastic shakedown, plastic shakedown or ratchetting occurs, and therefore many calculations are required to generate the Bree-like diagram [2].

In order to overcome the difficulties of the step-by-step elasto-plastic FEA, a number of direct methods based upon the Koiter's [3] kinematic and the Melan's [4] static theorems have been developed including: i) Uniform Modified Yield (UMY) surface method [5]; ii) the Generalized Local Stress Strain (GLOSS) r-node method [6]; iii) the Elastic Compensation Method (ECM) [7, 8]; iV) mathematical programming methods [9-11]; and V) the Linear Matching Method (LMM) [12-17]. The LMM has been shown to give accurate solutions to complex geometries and load histories [12, 13]. The LMM ABAQUS user subroutines [18] have been consolidated by the R5 [19] research program of British Energy Generation Ltd. (BEGL) to the commercial standard, and are now in extensive use for design and/or assess power plant components.

In this paper, the linear matching method is used to address upper bound and lower bound shakedown limits for a circumferential welded pipe subjected to a constant internal pressure and a varying thermal load history. The welded pipe is composed of three parts: i) the Parent Material (PM), ii) the Weld Metal (WM) and iii) the Heat Affected Zone (HAZ). Each of them is assumed to be an isotropic, elastic perfectly plastic material which satisfies the von Mises yield criterion.

The remainder of this paper comprises five parts. In section 2, the linear matching method is briefly described. Section 3 presents the pipe geometry and Material properties. This is followed by FE model of the pipe. Section 5 presents the shakedown analyses for the welded pipe. It also discusses the effects of WM geometry, ratio of inner radius to wall thickness and finally material properties of WM, HAZ and PM on the reverse plasticity limit, limit load and the gradient of the ratchet limit line, and offers equations characterising these effects. These equations are combined to generate a safety shakedown envelope for welded pipes within the ranges of the equations.

\section{Linear Matching Method}

The Linear Matching Method (LMM) states that if a linear material offers a stress which is the same as a yield condition for a given strain rate history $\dot{\varepsilon}^{i}$, shakedown solutions may be developed from linear solutions with a spatially varying shear modulus, $\mu$ [14,20-23]. For the von Mises yield criterion the relevant linear material is incompressible and the shear modulus $\mu$ is given by the matching condition 


$$
\mu=\frac{2 \sigma_{y}(\theta)}{3 \overline{\dot{\varepsilon}}^{i}}
$$

where $\sigma_{y}(\theta)$ is the temperature dependent yield stress and $\overline{\dot{\varepsilon}}$ is the effective strain rate.

Consider a body of volume, $V$, with a surface area $S$. The body is subjected to mechanical loads, $\lambda P\left(x_{i}, t\right)$, over a fraction of the surface area, $S_{T}$, and varying thermal loads $\lambda \theta\left(x_{i}, t\right) . \lambda$ is a load multiplier. These loads are applied over a time cycle $0 \leq t \leq \Delta t$. A zero displacement rate condition is applied over the remainder of the surface area, $S_{u}$ such that $\dot{u}_{i}=0$. The temperature independent Young's modulus $E$ and Poisson's ratio $v$ are adopted throughout, as the effects of temperature dependent elastic properties are not significant and hence ignored. The corresponding linear elastic stress history $\hat{\sigma}_{i j}$ is then given as

$$
\lambda \hat{\sigma}_{i j}\left(x_{i}, t\right)=\lambda \hat{\sigma}_{i j}^{\theta}\left(x_{i}, t\right)+\lambda \hat{\sigma}_{i j}^{P}\left(x_{i}, t\right)
$$

where $\hat{\sigma}_{i j}^{\theta}\left(x_{i}, t\right)$ and $\hat{\sigma}_{i j}^{p}\left(x_{i}, t\right)$ are elastic stress histories corresponding to $\theta\left(x_{i}, t\right)$ and $P\left(x_{i}, t\right)$, respectively. The cyclic stress history $\sigma_{i j}\left(x_{i}, t\right)$ over the time cycle is given by

$$
\sigma_{i j}\left(x_{i}, t\right)=\lambda \hat{\sigma}_{i j}\left(x_{i}, t\right)+\bar{\rho}_{i j}\left(x_{i}\right)
$$

where $\bar{\rho}_{i j}\left(x_{i}\right)$ is a constant residual stress.

On the basis of the Koiter's theorem [3], the upper bound shakedown limit $\lambda_{U B}$ is given as

$$
\lambda_{U B}=\frac{\int_{V}^{\Delta t} \int_{0} \sigma_{y} \overline{\dot{\varepsilon}}\left(\dot{\varepsilon}_{i j}\right) d t d V}{\int_{V}^{\Delta t} \int_{0} \hat{\sigma}_{i j} \dot{\varepsilon}_{i j} d t d V}
$$

where $\dot{\varepsilon}_{i j}$ is a kinematically admissible stain rate and $\overline{\dot{\varepsilon}}=\sqrt{\frac{2}{3} \dot{\varepsilon}_{i j} \dot{\varepsilon}_{i j}}$ is the effective strain rate. Then $\lambda_{U B} \geq \lambda_{s}$, where $\lambda_{s}$ is the exact shakedown limit.

Based on the Melan's theorem [4], the cyclic stress $\sigma_{i j}\left(x_{i}, t\right)$ should be equal to or less than the yield stress at all points in the body, i.e.

$$
f\left(\lambda_{L B} \hat{\sigma}_{i j}\left(x_{i}, t\right)+\bar{\rho}_{i j}\left(x_{i}\right)\right) \leq 0
$$

where $\lambda_{L B}$ is the lower bound shakedown limit. Then $\lambda_{L B} \leq \lambda_{s}$.

The linear matching method may be implemented in ABAQUS for a given load history. At each iteration, a linearised problem is solved for the changes of the stress, stain and displacement. At each integration point user sub-routines compute i) the varying shear modulus $\mu$; ii) the Jocobian matrix; iii) the constant residual stress and $\mathrm{iV}$ ) the updated stress for a given strain increment. Hence, the upper bound shakedown limit at each iteration may be calculated by integrating equation (4) over the 
volume, and is then used in the next iteration. The lower bound shakedown limit can be determined by checking the yield condition for all integration points[24].

\section{Welded Pipe Geometry and Material Properties}

Consider a circumferential welded pipe, including a single $\mathrm{V}$ butt weld with $\mathrm{V}$ root, subjected to a constant internal pressure $P$ (with closed end conditions) and a cyclic thermal load history (Fig. 1). The inhomogeneous pipe includes three different material domains - Parent Material (PM), Weld Metal (WM) and Heat Affected Zone (HAZ), each of which is isotropic, elastic perfectly plastic and satisfies the von Mises yield criterion. The initial residual stress in the pipe due to the welding process is considered to be zero due to post weld heat treatment. The length $L$, inner radius $R_{i}$, wall thickness $t$ and other five geometry parameters are shown in Fig. 1 and Table 1 . The material properties including the yield stress $\sigma_{y}$, Young's modulus $E$, Poisson's ratio $v$, conductivity $k$ and coefficient of thermal expansion $\alpha$ adopted in this paper for the baseline calculation are given in Table 2, where $\mathrm{HAZ}$ and PM share same values of $\sigma_{y}, E$ and $\alpha$; and WM, HAZ and PM have same values of $k$ and $v$.

\section{Finite Element Modelling}

Fig. 2 shows the two dimensional axisymmetric model used in this analysis, with a symmetry condition applied in the axial direction. The closed end condition of the pipe is simulated by applying an equivalent axial tension $q=P R_{i}{ }^{2} /\left(2 R_{i} t+t^{2}\right)$ and the end of the pipe is constrained to remain inplane, simulating the expansion of a long pipe.

It is assumed that the ambient air temperature outside of the pipe is $\theta_{0}$, and the operating temperature of the fluid contained within the pipe fluctuates between ambient and a higher value, $\theta_{0}+\Delta \theta$ (Fig. 3). Due to the dissimilar material in the pipe, the applied cyclic thermal loading may be constructed by three thermal stress extremes: i) a thermal stress field produced by a linear temperature gradient through the wall thickness; ii) a thermal stress field occurring at the highest uniform temperature due to the different thermal expansion coefficients and Young's modulus between the PM and WM; and iii) a zero thermal stress field simulating a uniform ambient temperature. If $\theta_{0}$ is zero, the maximum effective elastic thermal stresses for these three extremes can be determined by the maximum temperature difference $\Delta \theta$. Hence the thermal load history can be characterised by $\Delta \theta$. 
In this paper, the Abaqus type CAX8R 8-node biquadratic axisymmetric quadrilateral elements with reduced integration are used for structural analysis and DCAX8 8-node quadratic axisymmetric heat transfer quadrilateral elements with reduced integration scheme are used for the heat transfer analysis (Fig. 4).

\section{Results and Discussions}

\subsection{Upper and lower bound shakedown limits}

Fig. 5a shows von Mises effective elastic stress fields of the welded pipe subjected to an internal pressure $P=P_{0}=23 M P a$, which is applied as a reference mechanical load. The elastic stress fields of the welded pipe subjected to a linear temperature gradient through the wall thickness ( $\Delta \theta=\Delta \theta_{0}=50^{\circ} \mathrm{C}$ ) is referred to as the reference thermal stress, which is shown in Fig. $5 \mathrm{~b}$. The elastic stress fields corresponding to the highest uniform temperature of $50^{\circ} \mathrm{C}$ is given in Fig. 5c. This elastic thermal stress is produced by the material mismatch, which may play an important role in the shakedown limits.

Fig. 6 shows converged upper bound shakedown limits of the welded pipe, where a normalised internal pressure $P / P_{0}$ and a normalised temperature range $\Delta \theta / \Delta \theta_{0}$ are chosen as an ordinate and an abscissa in the diagram respectively. $P_{0}=23 \mathrm{MPa}$ and $\Delta \theta_{0}=50^{\circ} \mathrm{C}$ are the reference internal pressure and the reference temperature range, respectively. The interaction curve consists of line $\mathrm{AB}$ and curve $\mathrm{BC}$ which represent reverse plasticity limits and ratchet limits, respectively. Shakedown occurs when the applied load lies below $\mathrm{AB}$ and $\mathrm{BC}$, otherwise, either reverse plasticity appears beyond $\mathrm{AB}$ or ratchetting happens above $\mathrm{BC}$. The point $\mathrm{C}$ denotes the limit load for the applied mechanical load.

Fig. 6 also presents the converged values of the lower bound shakedown limits. In this paper, a convergence condition is given as $\left(\lambda_{U B}^{k}-\lambda_{L B}^{k}\right) / \lambda_{U B}^{k} \leq \delta$, where $\delta=1 \%, \lambda_{U B}^{k}$ and $\lambda_{L B}^{k}$ denote the upper and lower bound shakedown limit multipliers at $k^{\text {th }}$ iteration. Convergence is reached when this condition is satisfied for more than five consecutive iterations. Both limits are then assumed to converge to an exact value. The upper bound shakedown limit is therefore chosen as the shakedown limit in the rest of this paper. Fig. 7 shows the convergence reaches after 50 iterations for the computation of upper bound and lower bound reverse plasticity limits at point A (Fig. 6). It is worth noting that the upper bounds decrease monotonically to the converged value.

A comparison of shakedown limits between the welded pipe and the pure PM pipe is shown in Fig. 8a. The reverse plasticity limit of the welded pipe is reduced compared with that of the pure PM pipe, but the limit load is comparatively unaffected. The low cycle fatigue failure due to the local reverse 
plasticity may occur as the different stiffnesses of WM and PM cause a stress concentration. This local concentration has little effect on the global failure mechanism, and hence does little to affect the limit load. Further discussion of these mechanisms is given in section 4.

The reduced reverse plasticity limit shown is clearly harmful to the performance of the pipe. As an example of the scale of the reduction in performance, the reverse plasticity boundary was brought back to comparable levels of the pure PM pipe by increasing the yield stress of the WM to $460 \mathrm{MPa}$, shown in Fig. 8b.

In practice, the diagram in Fig. 6 may be simplified to be two lines and hence can be determined by three limits: (i) reverse plasticity limit; (ii) limit load and (iii) the slope of the ratchet limit line, where (i) defines the horizontal line $\mathrm{AB}$, and (ii) and (iii) build the slope line $\mathrm{BC}$.

\subsection{Effect of geometry parameters and material properties on the shakedown limits}

In this subsection, the individual effects of i) WM geometry, ii) ratio of inner radius to wall thickness and iii) material properties of WM, PM and HAZ on the shakedown limits of the weld pipe are investigated.

\subsubsection{Influence of WM geometry}

In order to detect the influence of WM geometry on the shakedown limits, five parameters $b, c, e$, $\alpha$ and $\beta$ [25] are separately considered to vary in values: $b=2,3,4,5,6(\mathrm{~mm}), c=2,2.5,3,3.5,4$ (mm), $e=4.5,5.5,6.5,7.5,8.5(\mathrm{~mm}), \alpha=43,48,53,58,63\left(^{\circ}\right)$ and $\beta=8,10,12,14,16\left(^{\circ}\right)$.

Fig. 9 shows the effect of varying $b$ dimension on the shakedown interaction diagram (keeping all other variables constant). A marginal increase in the reverse plasticity limit is observed with increasing $b$ value. This can be attributed to the effect of the $b$ dimension on the thermal stress distribution at the weld. The limit load is unaffected by the change in the $b$ dimension, since the change in the stress distribution is too small to have an impact on the global limit of the pipe.

Fig. 9 also shows the effect of $c, e, \alpha$ and $\beta$ on the shakedown limits, and shows that these dimensions also have very little effect on the shakedown loads of the pipe for similar reasons as with the case of parameter $b$.

In practice, it is concluded that the geometry of WM has very little effect on the reverse plasticity limits, limit loads and slopes of the ratchet limit line of the welded pipe. 


\subsubsection{Influence of ratio of inner radius to wall thickness}

The effects of the different ratios of the inner radius $R_{i}$ to wall thickness $t$ of the welded pipe on the shakedown limits are addressed in this subsection. The inner radius is varied between $40 \mathrm{~mm}$ and $600 \mathrm{~mm}$, with a fixed wall thickness of $40 \mathrm{~mm}$. The shakedown limit interaction diagrams are shown in Fig.10.

The reverse plasticity limits are shown to rise with an increasing $R_{i} / t$ ratio. The thermal stresses incurred in each geometry are similar, with a reduction in the thermal stress concentration seen in the region of the PM (where local failure occurs) with increasing $R_{i} / t$. The limit load is shown to decrease with increasing $R_{i} / t$, which is due to the increasing hoop and axial forces resulting from the increasing pressure loading area and the closed end condition. It is also noted that the slope of the ratchet limit lines increases with increasing $R_{i} / t$ ratio.

\subsubsection{Influence of materials properties}

In this subsection, the individual effects of the coefficient of thermal expansion $\left(\alpha^{\text {WM }}\right)$, the Young's modulus $\left(E^{W M}\right)$, the yield stress $\left(\sigma_{y}^{W M}\right)$ of the WM and the yield stress of the HAZ $\left(\sigma_{y}^{H A Z}\right)$ on the shakedown limits are independently investigated.

\subsubsection{Coefficient of thermal expansion of weld metal $\alpha^{\text {WM }}$}

The coefficient of thermal expansion of weld metal $\alpha^{\text {MM }}$ varies from $3.0\left(\times 10^{-5}{ }^{\circ} C^{-1}\right)$ to $4.6\left(\times 10^{-5}{ }^{\circ} C^{-1}\right)$ in $0.2\left(\times 10^{-5}{ }^{\circ} C^{-1}\right)$ increments. Fig. 11 shows that when $\alpha^{W M}<\alpha^{P M}$, the reverse plasticity limits rise with increasing $\alpha^{W M}$. Fig. 11 also shows that when $\alpha^{W M} \geq \alpha^{P M}$, the reverse plasticity limits fall with increasing $\alpha^{W M}$. This result arises because larger thermal stresses will occur where the difference in thermal expansion coefficients is larger, causing localised failure at lower thermal loads. The limit load of the structure is unaffected by the change in thermal expansion coefficient due to the purely mechanical nature of the load. The slopes of the ratcheting boundary vary with $\alpha^{W M}$ in a similar manner to the reverse plasticity boundary.

\subsubsection{Young's modulus of weld metal $E^{W M}$}


The Young's modulus of the weld metal $E^{W M}$ varies from $40 \mathrm{MPa}$ to $680 \mathrm{MPa}$ in $80 \mathrm{MPa}$ increments. Fig. 12 shows that the variation in $E^{W M}$ does not affect the limit loads since the localised effect of the stress concentration caused does not impact on the overall load carrying capability of the structure.

Fig. 12 also shows that when $E^{W M} / E^{P M}<1.8$, the reverse plasticity limits rise with increasing $E^{W M}$ and when $E^{W M} / E^{P M} \geq 1.8$, the reverse plasticity limits fall with increasing $E^{W M}$. Similarly to the case of $\alpha^{W M}$, this is because a larger difference in stiffnesses between the WM and PM will lead to a larger thermal stress concentration, causing localised failure at lower thermal loads. It is also noted that the slopes of the ratcheting boundary decrease with increasing $E^{W M}$.

\subsubsection{Yield stress of weld metal $\sigma_{y}^{w M}$}

The yield stress of the weld metal $\sigma_{y}^{W M}$ varies from $172.5 \mathrm{MPa}$ to $460 \mathrm{MPa}$ in $57.5 \mathrm{MPa}$ increments. Fig. 13 shows that the variation in $\sigma_{y}^{W M}$ does not affect the limit loads since globalised failures always occur at the PM region within the specified ranges.

Fig. 13 also shows that when $\sigma_{y}^{W M} / \sigma_{y}^{P M}<1.25$, the reverse plasticity limits rise with increasing $\sigma_{y}^{W M}$ and when $\sigma_{y}^{W M} / \sigma_{y}^{P M} \geq 1.25$, the reverse plasticity limits do not change with increasing $\sigma_{y}^{W M}$. This result arises because (i) when $\sigma_{y}^{W M} / \sigma_{y}^{P M}<1.25$, the largest thermal stress causing localised failure will occur at WM area, and so a larger $\sigma_{y}^{W M}$ will allow larger thermal loads, shown in Fig. 14a and (ii) when $\sigma_{y}^{W M} / \sigma_{y}^{P M} \geq 1.25$, the largest thermal stress will occur at HAZ or PM area (shown in Fig. 14b, c) where the variation in $\sigma_{y}^{W M}$ does not affect the thermal loads. It is also noted that the ratchet limit line slopes are not affected by $\sigma_{y}^{W M}$.

\subsubsection{Yield stress of heat affected zone $\sigma_{y}^{\text {HAZ }}$}

The HAZ is a thin band with a width of $2.5 \mathrm{~mm}$. The yield stress of HAZ $\sigma_{y}^{H A Z}$ varies from $184 \mathrm{MPa}$ to $230 \mathrm{MPa}$ in $11.5 \mathrm{MPa}$ increments. Fig. 15 shows that the variation in $\sigma_{y}^{\text {HAZ }}$ does not affect the limit loads since globalised failures always occur at the PM region within the specified ranges. Fig. 15 also shows that the reverse plasticity limits rise with increasing $\sigma_{y}^{H A Z}$ since the largest thermal stress occurs at HAZ area where the larger $\sigma_{y}^{H A Z}$ leads to higher thermal loads. It can also be seen that the ratchet limit line slopes are not affected by $\sigma_{y}^{H A Z}$. 


\subsection{Influence of temperature dependent yield stress}

In this paper, the yield stress was considered not to vary significantly within the temperature range considered (which was less than $100^{\circ} \mathrm{C}$ ). Clearly, however, variation of yield stress with temperature is an important factor when higher temperatures are considered or a larger variation of yield stress is observed. Table 3 gives temperature-dependent yield stresses of the welded pipe [1] and Fig. 16 gives an example of how the shakedown limit diagram is affected by this. From the figure, a reduction of less than $50 \mathrm{MPa}$ over a $200^{\circ} \mathrm{C}$ temperature range can cause sizeable reductions to the shakedown boundary, which emphasizes the importance of this effect in shakedown calculations.

\section{4. Safety shakedown envelope}

In previous subsections, results show that i) the reverse plasticity limits of the welded pipe were affected by the ratio of inner radius to wall thickness $r^{d}$, the ratio of thermal expansion coefficient $r^{\alpha^{W P}}$, the ratio of Young's modulus $r^{E^{W P}}$, the ratio of yield stress $r^{\sigma_{y}^{W P}}$ and the ratio $r^{\sigma_{y}^{H P}}$; ii) limit loads were affected by $r^{d}$ only and iii) the slopes of the ratchet limit line were affected by $r^{d}, r^{\alpha^{W P}}$ and $r^{E^{W P}}$. These effects are then combined to allow the creation of a safety shakedown envelope, which can be used for the design of any welded pipes within the specified ranges, shown in Fig. 17. $P$ is the applied internal pressure and $\Delta \theta$ is the applied temperature range. $\Delta \theta_{u}$ represents the design temperature range causing reverse plasticity limit, $P_{u}$ denotes the design internal pressure causing limit load and $S_{u}$ is the design slope of the ratchet limit line. Three design limits are formulated as

$$
\begin{aligned}
& \quad \Delta \theta_{u}=\Delta \theta_{P M} f_{1}\left(r^{d}\right) f_{2}\left(r^{\alpha^{W P}}\right) f_{3}\left(r^{E^{W P}}\right) f_{4}\left(r^{\sigma_{y}^{W P}}\right) f_{5}\left(r^{\sigma_{y}^{H P}}\right) \\
& P_{u}=P_{P M} g_{1}\left(r^{d}\right) \\
& S_{u}=S_{P M} h_{1}\left(r^{d}\right) h_{2}\left(r^{\alpha^{W P}}\right) h_{3}\left(r^{E^{W P}}\right)
\end{aligned}
$$

where

$$
r^{d}=\frac{R_{i}}{t}, \quad r^{\alpha^{W P}}=\frac{\alpha^{W M}}{\alpha^{P M}}, \quad r^{E^{W P}}=\frac{E^{W M}}{E^{P M}}, \quad r^{\sigma_{y}^{W P}}=\frac{\sigma_{y}^{W M}}{\sigma_{y}^{P M}} \quad \text { and } \quad r^{\sigma_{y}^{H P}}=\frac{\sigma_{y}^{H A Z}}{\sigma_{y}^{P M}}
$$

$\Delta \theta_{P M}, P_{P M}$ and $S_{P M}$ are constant values representing the calculated temperature range causing reverse plasticity limit, the limit internal pressure and the slope of the ratchet limit line for a pure PM pipe with $r^{d}=7.5$ : 


$$
\Delta \theta_{P M}=0.355 \sigma_{y}^{P M}\left({ }^{\circ} \mathrm{C}\right) \quad P_{P M}=0.146 \sigma_{y}^{P M}(\mathrm{MPa}) \quad \text { and } \quad S_{P M}=5.43\left({ }^{\circ} \mathrm{C} / \mathrm{MPa}\right)
$$

where $\sigma_{y}^{P M}$ is the yield stress of PM. The unit of $\sigma_{y}^{P M}$ in Equation (10) is MPa.

$f_{1}\left(r^{d}\right), f_{2}\left(r^{\alpha^{W P}}\right), f_{3}\left(r^{E^{W P}}\right), f_{4}\left(r^{\sigma_{y}^{W P}}\right)$ and $f_{5}\left(r^{\sigma_{y}^{H P}}\right)$ are the individual influence functions on the reverse plasticity limits, $g_{1}\left(r^{d}\right)$ is the influence function on the limit internal pressure and $h_{1}\left(r^{d}\right), h_{2}\left(r^{\alpha^{W P}}\right)$, $h_{3}\left(r^{E^{W P}}\right)$ are the influence functions on the slope of the ratchet limit line, respectively.

In order to calculate the shakedown limits for a specific case, the values of each influence function is required. For the determination of these influence functions, the obtained reverse plasticity limits, limit internal pressures and the slopes of the ratchet limit line in Figs. 10-13, 15 are normalised and replotted in graphs of function $f, g$ and $h$ against the ratios respectively as shown in Figs. 18-20. Trend lines are fit to the data to give the influence functions, shown in Equations (11-19).

$$
\begin{aligned}
& f_{1}\left(r^{d}\right)=0.87\left(r^{d}\right)^{0.064} \\
& 1.0 \leq r^{d} \leq 15.0 \\
& f_{2}\left(r^{\alpha^{W P}}\right)=\left\{\begin{array}{lc}
0.98 r^{\alpha^{W P}}+0.071 & 0.79 \leq r^{\alpha^{W P}} \leq 0.95 \\
0.0099 r^{\alpha^{W P}}+0.99 & 0.95<r^{\alpha^{W P}} \leq 1.11 \\
-0.71 r^{\alpha^{W P}}+1.78 & 1.11<r^{\alpha^{W P}} \leq 1.21
\end{array}\right. \\
& f_{3}\left(r^{E^{W P}}\right)= \begin{cases}-0.33\left(r^{E^{W P}}\right)^{2}+0.86 r^{E^{W P}}+0.43 & 0.2 \leq r^{E^{W P}} \leq 1.4 \\
-0.0071 r^{E^{W P}}+1.01 & 1.4<r^{E^{W P}} \leq 2.6 \\
-0.23 r^{E^{W P}}+1.58 & 2.6<r^{E^{W P}} \leq 3.4\end{cases} \\
& f_{4}\left(r^{\sigma_{y}^{W P}}\right)= \begin{cases}0.76 r^{\sigma_{y}^{W P}}+0.045 & 0.75 \leq r^{\sigma_{y}^{W P}} \leq 1.25 \\
1 & 1.25<r^{\sigma_{y}^{W P}} \leq 2.0\end{cases} \\
& f_{5}\left(r^{\sigma_{y}^{H P}}\right)=1.00033 r^{\sigma_{y}^{H P}}-0.00036 \quad 0.8 \leq r^{\sigma_{y}^{H P}} \leq 1.0 \\
& g_{1}\left(r^{d}\right)=5.77\left(r^{d}\right)^{-0.88} \quad 1.0 \leq r^{d} \leq 15.0 \\
& h_{1}\left(r^{d}\right)=0.13 r^{d}+0.054 \quad 1.0 \leq r^{d} \leq 15.0 \\
& h_{2}\left(r^{\alpha^{W P}}\right)= \begin{cases}0.092 r^{\alpha^{W P}}+0.91 & 0.79 \leq r^{\alpha^{W P}} \leq 1.0 \\
-0.21 r^{\alpha^{W P}}+1.22 & 1.0<r^{\alpha^{W P}} \leq 1.21\end{cases} \\
& h_{3}\left(r^{E^{W P}}\right)= \begin{cases}1.021\left(r^{E^{W P}}\right)^{-0.074} & 0.2 \leq r^{E^{W P}} \leq 1.4 \\
-0.039 r^{E^{W P}}+1.054 & 1.4 \leq r^{E^{W P}} \leq 3.4\end{cases}
\end{aligned}
$$


The shakedown envelope is designed for the welded pipes within the ranges of $r^{d}=1.0 \sim 15.0$; $r^{\alpha^{W P}}=0.79 \sim 1.21 ; r^{E^{W P}}=0.2 \sim 3.4 ; r^{\sigma_{y}^{W P}}=0.75 \sim 2.0$ and $r^{\sigma_{y}^{H P}}=0.8 \sim 1.0$. For an welded pipe, the values of ratio of inner radius to wall thickness $r^{d}$, the ratio of thermal expansion coefficient $r^{\alpha^{W P}}$, the ratio of Young's modulus $r^{E^{W P}}$, the ratio of yield stress $r^{\sigma_{y}^{W P}}$ and the ratio $r^{\sigma_{y}^{H P}}$ are determined by the geometry and material properties using Eq. 9. These ratios lead to the calculation of the influence functions $f_{1-5}, g_{1}$ and $h_{1-3}$ by the use of Eqs.11-19. Based upon the Eqs.6-8 and 10, the design temperature range associated with reverse plasticity limit $\Delta \theta_{u}$, the design limit internal pressure $P_{u}$ and the design slope of the ratchet limit line $S_{u}$ are calculated. A safety shakedown envelope is then built. If the applied load point $(P, \Delta \theta)$ lies inside the envelop in Fig.17, the welded pipe behaves shakedown, otherwise non-shakedown.

\section{Conclusions}

This paper presents the shakedown analysis on circumferential welded pipes subjected to a constant internal pressure and a cyclic thermal load. Based on the results obtained in this study, the following conclusions are given:

1) Comparing to a pure PM pipe, the discontinuity in material due to WM may lead to the significant change in the temperature range causing reverse plasticity limit, but does not significantly alter the internal pressure causing limit load.

2) Geometry changes to the WM do not affect shakedown limits of welded pipes.

3) A decrease in the ratio of the inner radius to wall thickness decreases the reverse plasticity limit but significantly increases the mechanical limit load of the welded pipe.

4) Material properties of WM and HAZ significantly affect the reverse plasticity limit, but the limit load is unaffected by these changes in material properties.

5) A safety shakedown envelope is created for the design of any welded pipes within the specified ranges.

6) The Linear Matching Method (LMM) is successfully applied in this study. It offers a monotonically decreased and converged upper bound shakedown limit.

\section{Acknowledgements}


The authors gratefully acknowledge the support of the Engineering and Physical Sciences Research Council of the United Kingdom (EP/G038880/1), and the University of Strathclyde during the course of this work.

\section{References}

[1] Brickstad B, Josefson BL, A parameter study of residual stress in multi-pass butt-welded stainless steel pipes. International Journal of Pressure Vessels and Piping, 1998;75:11-25

[2] Bree J, Plastic deformation of a closed tube due to interaction of pressure stresses and cyclic thermal stresses. International Journal of Mechanical Sciences, 1989; 31(11-12):865-892.

[3] Koiter WT, General theorems for elastic plastic solids. Progress in solid mechanics, Sneddon JN and Hill R, eds., North Holland, Amsterdam, 1960;1:167-221

[4] Melan E, Theorie statisch unbestimmter systeme aus ideal-plastichem baustoff. Sitzungsber. d. Akad. d. Wiss., 1936; Wien 2A(145):195-218

[5] Abou-Hanna J, McGreevy TE, A simplified ratcheting limit method based on limit analysis using modified yield surface. International Journal of Pressure Vessels and Piping, 2011;88:11-18

[6] Seshadri R, Inelastic evaluation of mechanical and structural components using the generalized local stress strain method of analysis. Nuclear Engineering and Design, 1995;153(2-3):287-303

[7] Mackenzie D, Boyle JT, Hamilton R, Shi J, Elastic compensation method in shell-based design by analysis. Proceedings of the 1996 ASME Pressure Vessels and Piping Conference, 1996;338:203-208

[8] Mackenzie D, Boyle JT, Hamilton R, The elastic compensation method for limit and shakedown analysis: a review. Trans IMechE, Journal of Strain Analysis for Engineering Design, 2000;35(3):171-188

[9] Liu YH, Carvelli V, Maier G, Integrity assessment of defective pressurized pipelines by direct simplified methods. International Journal of Pressure Vessels and Piping, 1997;74:49-57

[10] $\mathrm{Vu}$ DK, Yan AM, Nguyen-Dang H, A primal-dual algorithm for shakedown analysis of structures. Computer Method in Applied Mechanics and Engineering, 2004;193:4663-4674

[11] Staat M, Heitzer M, LISA a European project for FEM-based limit and shakedown analysis. Nuclear Engineering and Design, 2001;206:151-166

[12] Chen HF, Ponter ARS, Shakedown and limit analyses for 3-D structures using the Linear Matching Method. International Journal of Pressure Vessels and Piping, 2001;78:443-451 
[13] Chen HF, Ponter ARS, Integrity assessment of a 3D tubeplate using the linear matching method. Part 1. Shakedown, reverse plasticity and ratchetting, International Journal of Pressure Vessels and Piping, 2005; $82(2): 85-94$

[14] Chen HF, Ponter ARS, A Method for the Evaluation of a Ratchet Limit and the Amplitude of Plastic Strain for Bodies Subjected to Cyclic Loading. European Journal of Mechanics, A/Solids, 2001;20(4):555-571

[15] Chen HF, Ponter ARS, Ainsworth RA, The Linear Matching Method applied to the high temperature life integrity of structures, Part 1: Assessments involving constant residual stress fields. International Journal of Pressure Vessels and Piping, 2006;83(2):123-135

[16] Chen HF, Ponter ARS, Ainsworth RA, The Linear Matching Method applied to the high temperature life integrity of structures, Part 2: Assessments beyond shakedown involving changing residual stress fields. International Journal of Pressure Vessels and Piping, 2006;83(2):136-147

[17] Chen HF, Ponter ARS, Linear Matching Method on the evaluation of plastic and creep behaviours for bodies subjected to cyclic thermal and mechanical loading. International Journal for Numerical Methods in Engineering, 2006;68:13-32

[18] Tipping DJ, The Linear Matching Method: A guide to the ABAQUS user subroutines. E/REP/BBGB/0017/GEN/07, British Energy Generation Ltd., 2007

[19] Ainsworth RA (editor), R5: an assessment procedure for the high temperature response of structures. British Energy Generation Ltd., 2003;(3)

[20] Ponter ARS, Engelhardt M, Shakedown limits for a general yield condition: implementation and application for a von Mises yield condition. European Journal of Mechanics - A/Solids, 2000;19(3): 423-445

[21] Ponter ARS, Fuschi P, Engelhardt M, Limit analysis for a general class of yield conditions. European Journal of Mechanics, A/Solids, 2000;19(3):401-422

[22] Ponter ARS, and Chen HF, A minimum theorem for cyclic loading in excess of shakedown, with applications to the evaluation of a ratchet limit. European Journal of Mechanics A/Solids, 2001;20: 539-554

[23] Ponter ARS, The Linear Matching Method for the evaluation of limit loads, shakedown limits and related problems. Variational Formulations in Mechanics in Theory and Applications, Ed Taroco E., de Souza Neto and Novotny, CIMNE, Barcelona, Spain, 243-262

[24] Chen HF, Lower and upper bound shakedown analysis of structures with temperature-dependent yield stress. ASME Journal of Pressure Vessel Technology 2010;132(1):011202-1

[25] British Standard: Specification for "Metal-arc welding with covered electrode, gas-shielded metal-arc welding and gas welding-Joint preparations for steel", BS EN 29692:1994 


\section{Nomenclature}

$b, c, e, \alpha, \beta$ geometry parameters of the WM

$e_{1} \quad$ width of $\mathrm{HAZ}$

$E^{P M}, E^{W M}, E^{H A Z} \quad$ Young's modulus of PM, WM and HAZ, respectively

$f_{1-5} \quad$ influence functions on the reverse plasticity limits

$g_{1} \quad$ influence function on the limit internal pressure

$h_{1-3} \quad$ influence functions on the slope of the ratchet limit line

$k \quad$ conductivity

$P, P_{0} \quad$ applied internal pressure and reference internal pressure, respectively

$P_{u}, \Delta \theta_{u}, S_{u} \quad$ design internal pressure, design temperature range, and design slope of the ratchet limit line, respectively

$P_{P M}, \Delta \theta_{P M}, S_{P M} \quad$ calculated internal pressure, temperature range, and slope of the ratchet limit line for a pure PM pipe with $r^{d}=7.5$

PM, WM, HAZ parent material, weld metal, and heat affected zone, respectively

$q \quad$ equivalent axial tension

$R_{i}, D, L$ inner radius, diameter, and length of the pipe

$r^{d}, r^{\sigma_{y}^{H P}}$ ratio of inner radius to wall thickness, and ratio of yield stress between HAZ and PM, respectively

$r^{\alpha^{W P}}, r^{E^{W P}}, r^{\sigma_{y}^{W P}} \quad$ ratio of thermal expansion coefficient, ratio of Young's modulus, and ratio of yield stress between WM and PM, respectively

$t \quad$ wall thickness of the pipe

$\alpha^{P M}, \alpha^{W M}, \alpha^{H A Z}$ coefficient of thermal expansion of PM, WM and HAZ, respectively

$\delta \quad$ tolerance

$\varepsilon, \dot{\varepsilon}, \overline{\dot{\varepsilon}} \quad$ strain, strain rate, and effective strain rate, respectively

$\theta, \Delta \theta, \Delta \theta_{0} \quad$ temperature, temperature range, and reference temperature range

$\lambda, \lambda_{U B}, \lambda_{L B}, \lambda_{s} \quad$ load multiplier, upper bound shakedown limit, lower bound shakedown limit and exact shakedown limit, respectively

$\mu \quad$ shear modulus

$v \quad$ Poisson's ratio

$\bar{\rho} \quad$ constant residual stress

$\sigma_{y}, \sigma_{y}^{P M}, \sigma_{y}^{W M}, \sigma_{y}^{H A Z}$ yield stress, yield stress of PM, yield stress of WM, and yield stress of HAZ, respectively

$\sigma, \hat{\sigma} \quad$ cyclic stress and linear elastic stress, respectively

$\hat{\sigma}^{\theta}, \hat{\sigma}^{P} \quad$ elastic stress corresponding to $\theta$ and $P$ 
Table 1 Shape parameters of a welded pipe $[1,24]$

\begin{tabular}{|c|c|c|c|c|c|c|c|c|}
\hline$L(\mathrm{~mm})$ & $R_{i}(\mathrm{~mm})$ & $t(\mathrm{~mm})$ & $e_{1}(\mathrm{~mm})$ & $e(\mathrm{~mm})$ & $b(\mathrm{~mm})$ & $c(\mathrm{~mm})$ & $\alpha\left(^{\circ}\right)$ & $\beta\left(^{\circ}\right)$ \\
\hline 1000 & 300 & 40 & 2.5 & 4.5 & 3 & 2 & 63 & 10 \\
\hline
\end{tabular}

Table 2 Material properties at room temperature [1]

\begin{tabular}{|c|c|c|c|c|c|c|c|}
\hline $\begin{array}{c}\sigma_{y}^{P M} \\
(\mathrm{MPa})\end{array}$ & $\begin{array}{c}\sigma_{y}^{W M} \\
(\mathrm{MPa})\end{array}$ & $\begin{array}{c}E^{P M} \\
(\mathrm{GPa})\end{array}$ & $\begin{array}{c}E^{W M} \\
(\mathrm{GPa})\end{array}$ & $\begin{array}{c}\alpha^{P M} \\
\left(\times 10^{-5}{ }^{\circ} \mathrm{C}^{-1}\right)\end{array}$ & $\begin{array}{c}\alpha^{W M} \\
\left(\times 10^{-5}{ }^{\circ} \mathrm{C}^{-1}\right)\end{array}$ & $\begin{array}{c}k \\
\left(\mathrm{Wm}^{-1} \mathrm{C}^{-1}\right)\end{array}$ & $v$ \\
\hline 230 & 460 & 200 & 280 & 3.8 & 3.6 & 15 & 0.3 \\
\hline
\end{tabular}

Table 3. Temperature-dependent yield stress $\sigma_{y}$ of PM and WM, where HAZ shares the same $\sigma_{y}$ with PM [24].

\begin{tabular}{|c|c|c|c|c|c|c|c|}
\hline Temperature $\theta\left({ }^{\circ} \mathrm{C}\right)$ & $\leq 20$ & 200 & 400 & 600 & 800 & 1000 & $\geq 1200$ \\
\hline Yield stress $\sigma_{y}^{P M}=\sigma_{y}^{H A Z}(\mathrm{MPa})$ & 230 & 184 & 132 & 105 & 77 & 50 & 10 \\
\hline Yield stress $\sigma_{y}^{W M}(\mathrm{MPa})$ & 460 & 367 & 264 & 209 & 154 & 50 & 10 \\
\hline
\end{tabular}



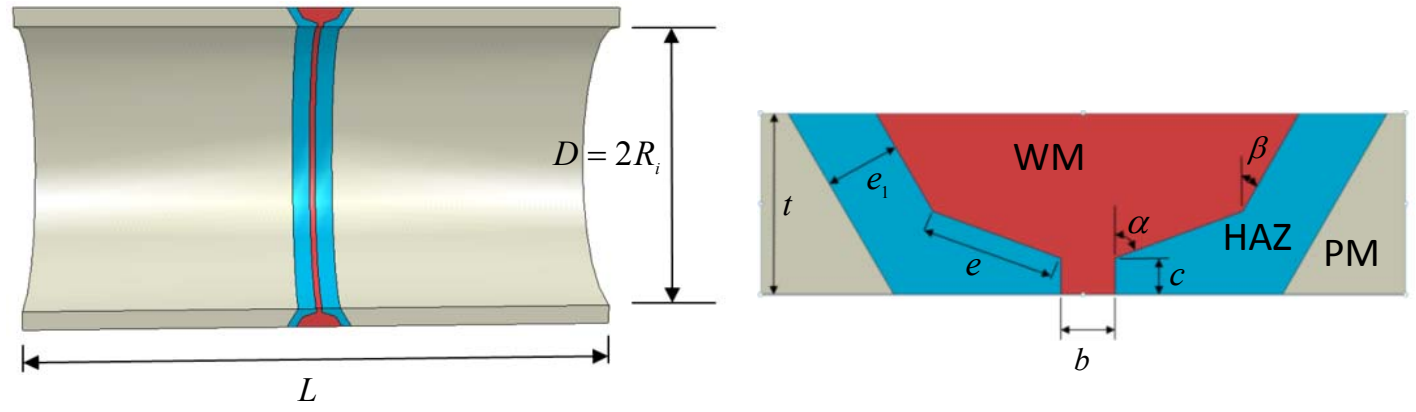

Fig.1 A welded pipe configuration

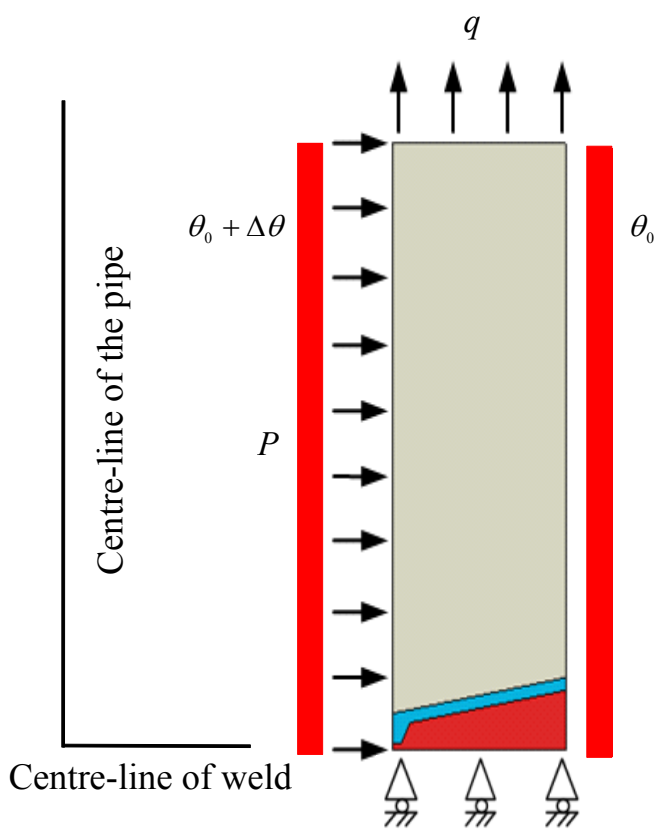

Fig. 2 Mechanical and thermal loads and boundary conditions of the welded pipe 


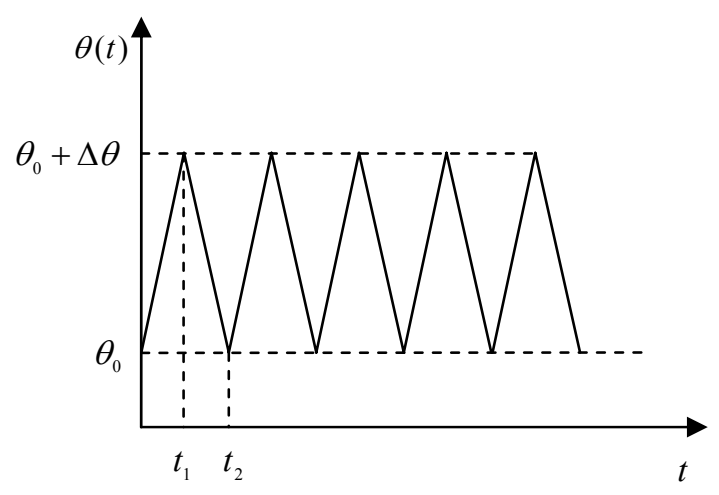

Fig. 3 The operating temperature history of the fluid contained within the welded pipe

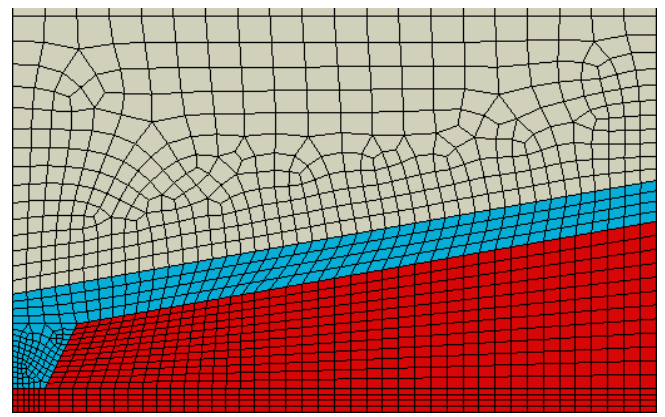

Fig. 4 Finite element mesh of the welded pipe 


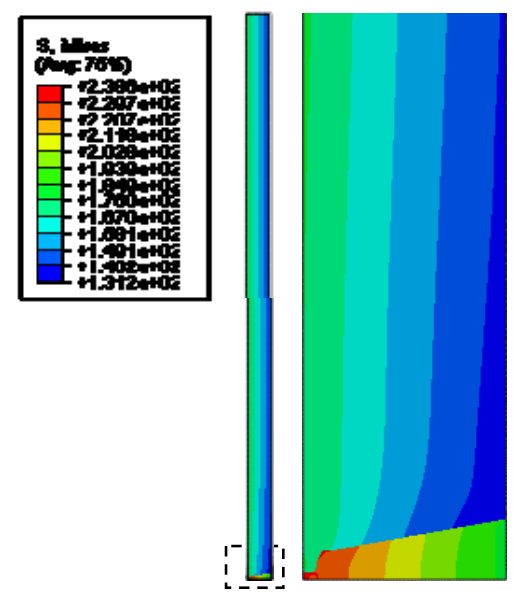

(a)

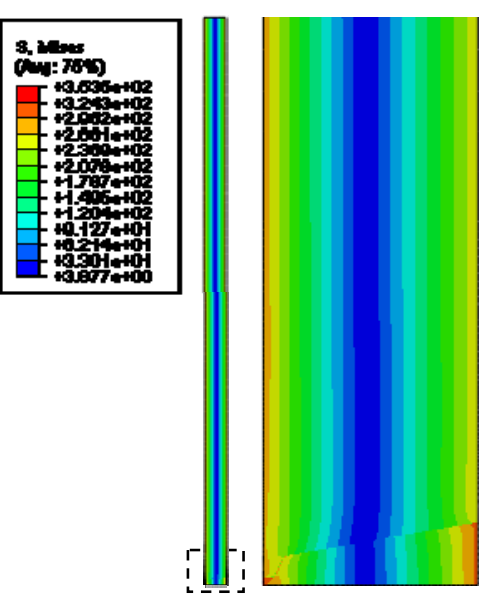

(b)

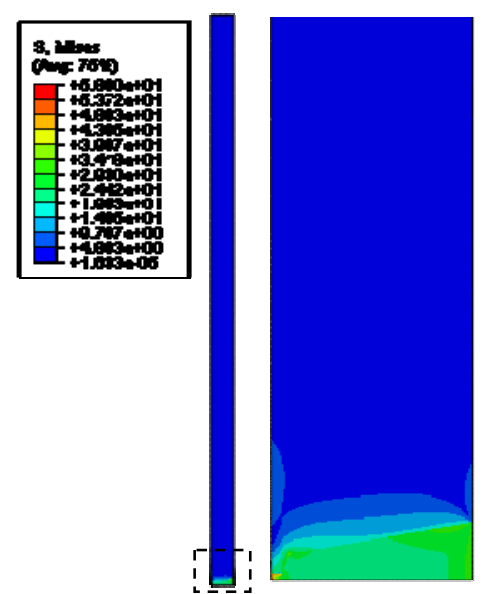

(c)

Fig. 5 The contours of von Mises effective elastic stress for a welded pipe and their zooms with (a) an internal pressure $P_{0}=23 \mathrm{MPa}$, (b) a linear temperature gradient $\left(\Delta \theta=\Delta \theta_{0}=50^{\circ} \mathrm{C}\right)$ and (c) the highest uniform temperature of $50^{\circ} \mathrm{C}$

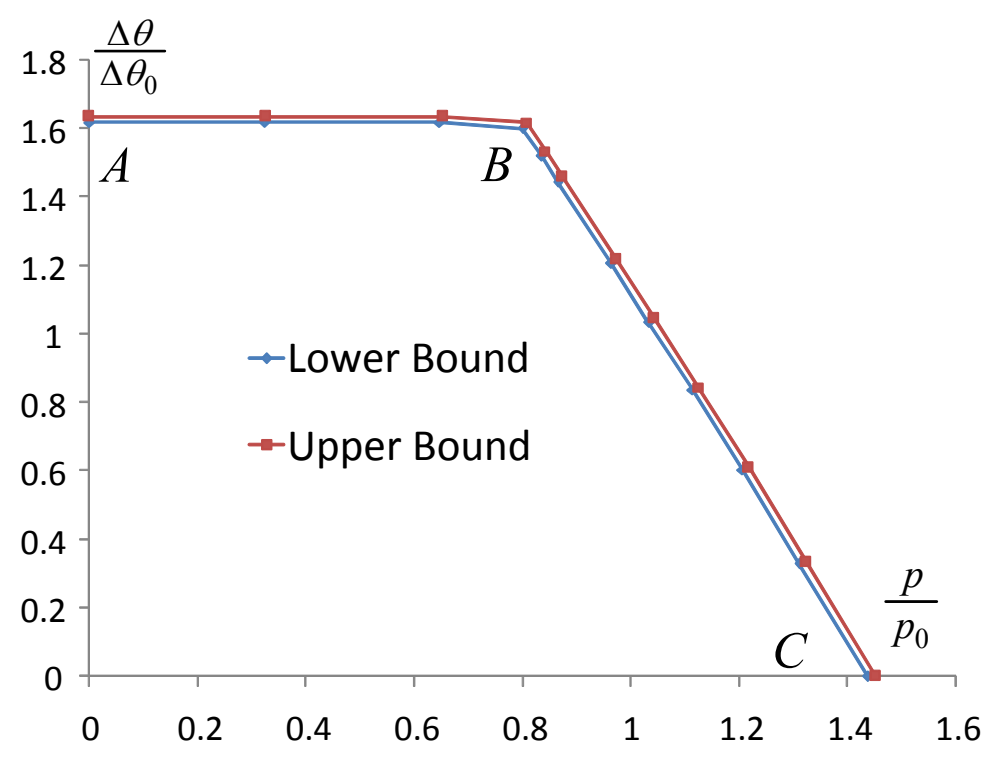

Fig. 6 Upper and lower bound shakedown limit interaction curves of a welded pipe subjected to a varying thermal load and a constant internal pressure 


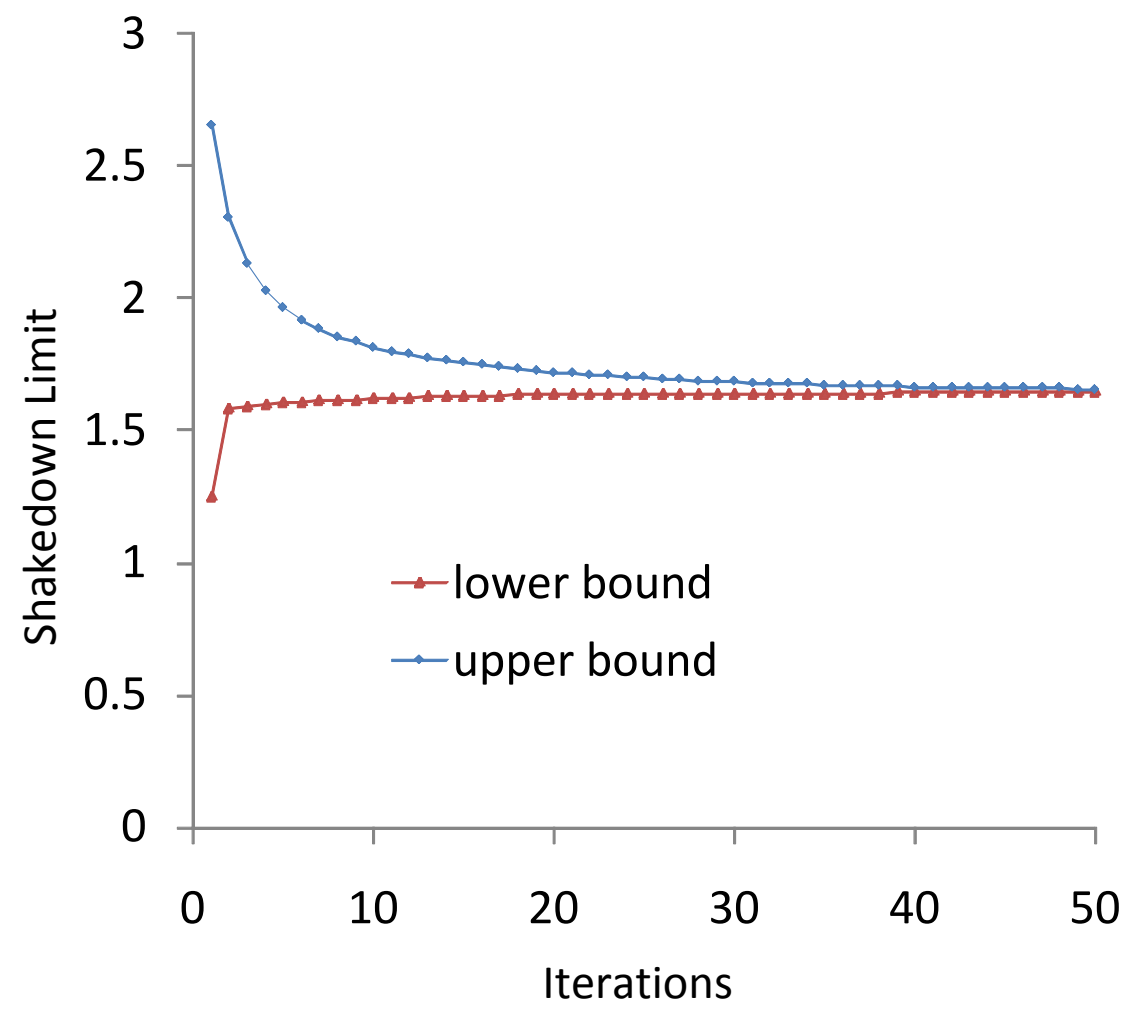

Fig. 7 The convergence condition of iterative processes for reverse plasticity limit (point A in Fig. 6, subjected to varying thermal loads only)

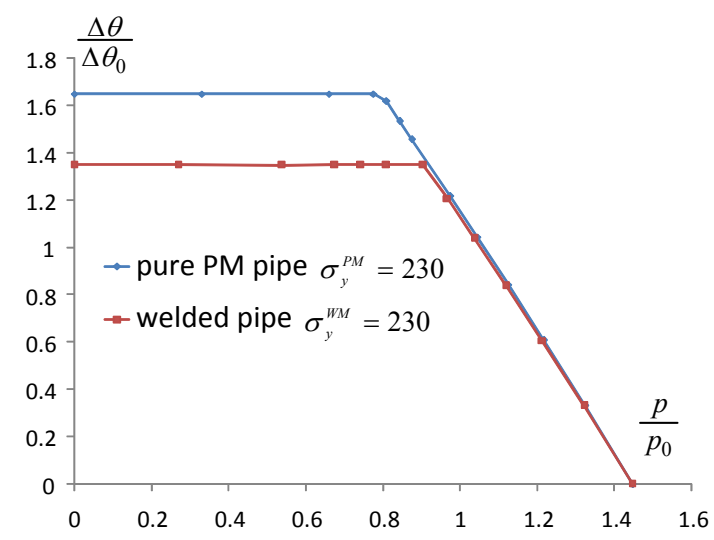

(a)

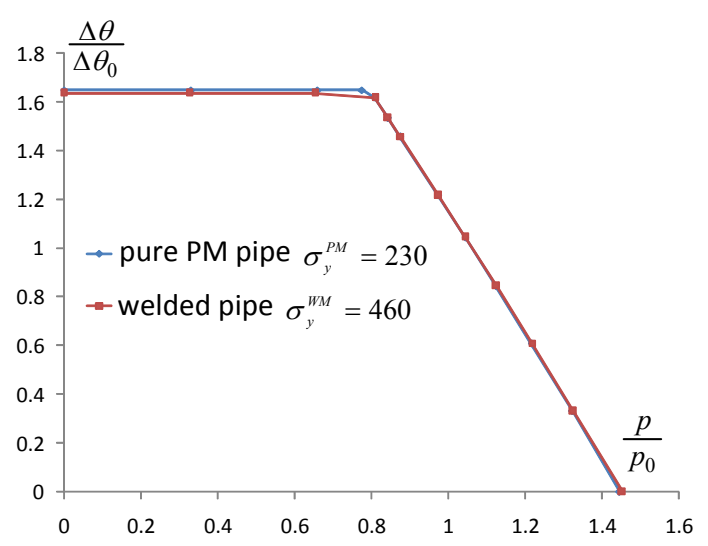

(b)

Fig. 8 Shakedown limit interaction curves of (a) the welded pipe with $\sigma_{y}^{W M}=230 M P a$ and the pure PM pipe and (b) the welded pipe with $\sigma_{y}^{W M}=460 \mathrm{MPa}$ and the pure PM pipe. In both cases, Young's modulus $E^{P M}=E^{H A Z}=200 G P a$ and $E^{W M}=280 G P a$ are adopted (Table 2) 


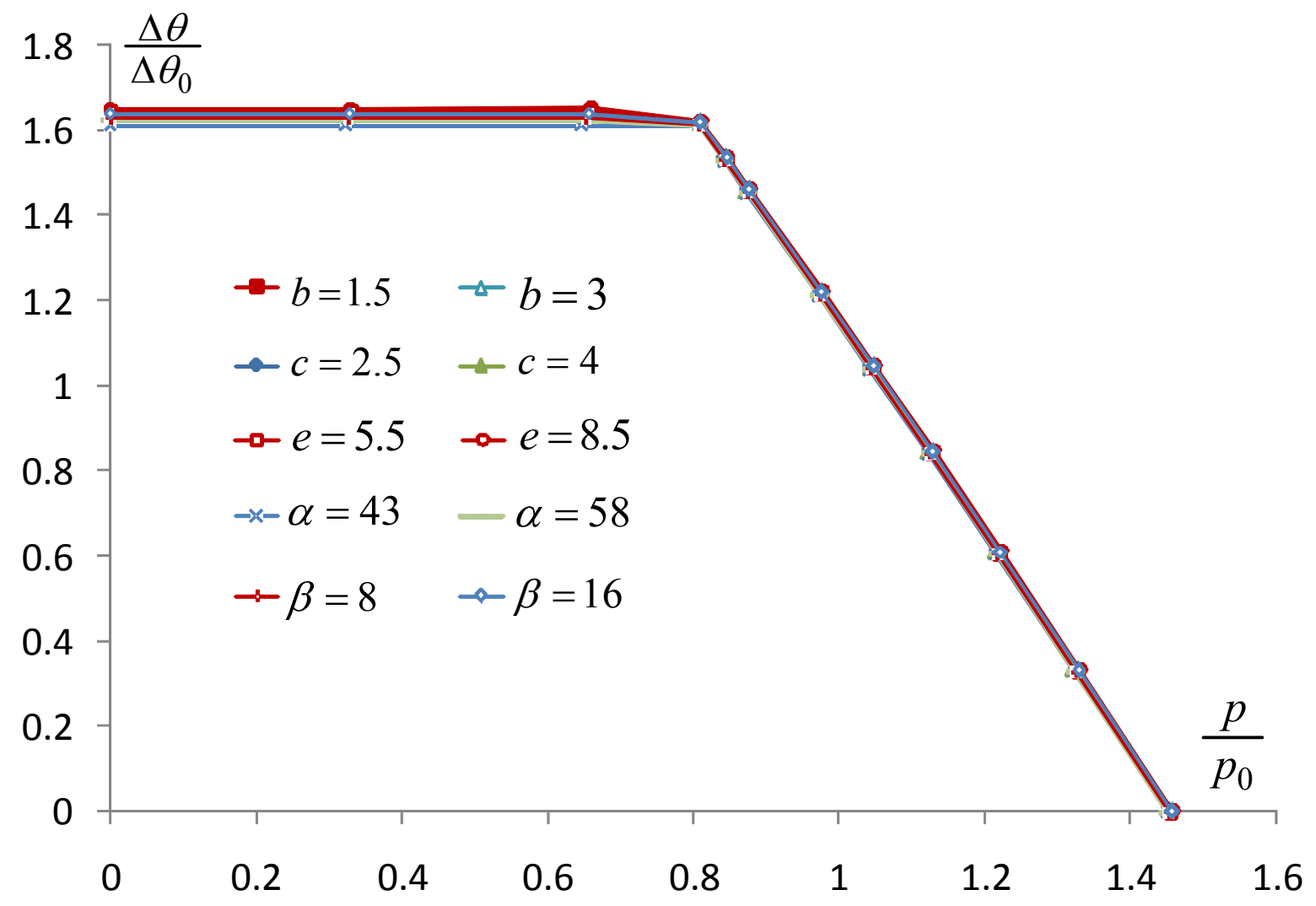

Fig. 9 Shakedown limit interaction curves of the welded pipe with the different values of $b(\mathrm{~mm}), c$ (mm), $e(\mathrm{~mm}), \alpha\left({ }^{\circ}\right)$ and $\beta\left({ }^{\circ}\right)$, where the wall thickness $t=40 \mathrm{~mm}$

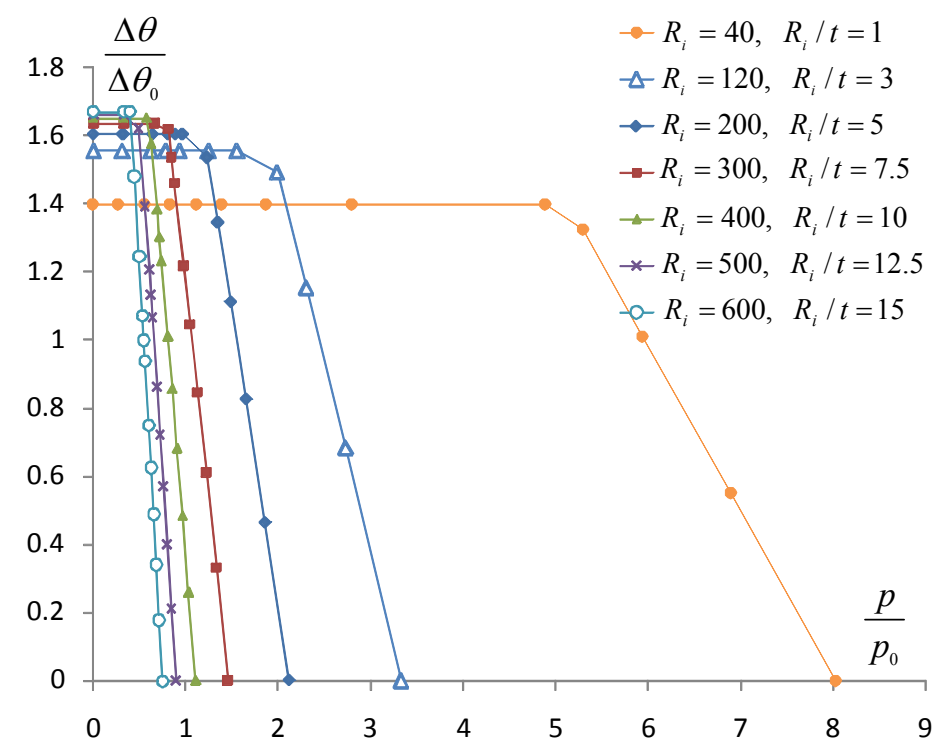

Fig. 10 Shakedown limit interaction curves of the welded pipe with the different ratios of the inner radius to wall thickness $R_{i} / t$ 


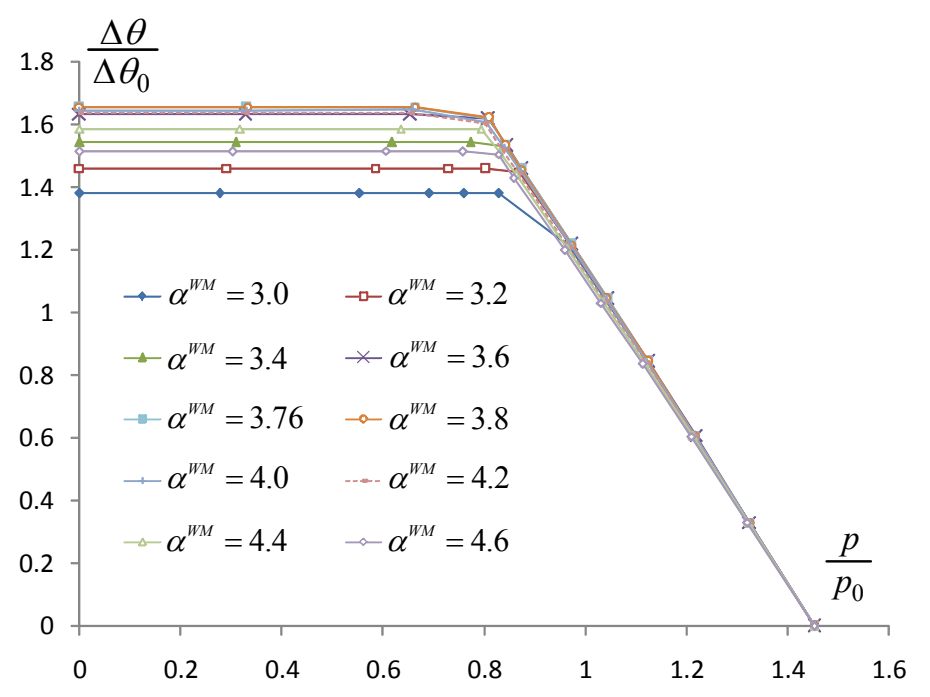

Fig. 11 Shakedown limit interaction curves of the welded pipe with the different coefficients of thermal expansion of the weld metal $\alpha^{W M}$, where $\alpha^{P M}=\alpha^{H A Z}=3.8\left(\times 10^{-5}{ }^{\circ} C^{-1}\right)$

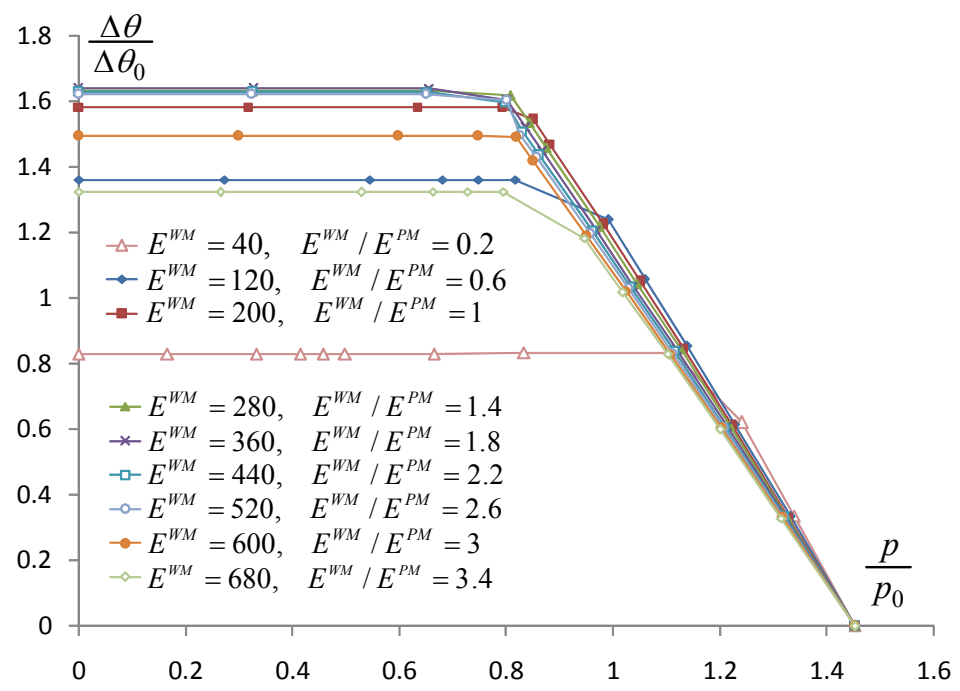

Fig. 12 Shakedown limit interaction curves of the welded pipe with the different Young's modulus of the weld metal $E^{W M}$, where $E^{P M}=E^{H A Z}=200 M P a$ 


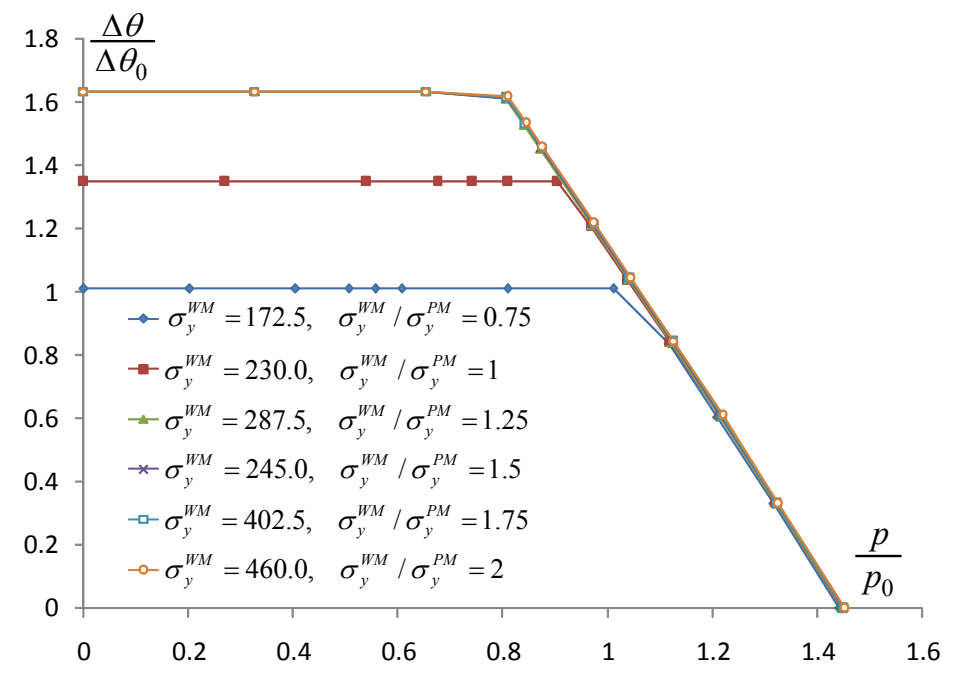

Fig. 13 Shakedown limit interaction curves of the welded pipe with the different yield stresses of the weld metal $\sigma_{y}^{W M}$, where $\sigma_{y}^{P M}=\sigma_{y}^{H A Z}=230 M P a$

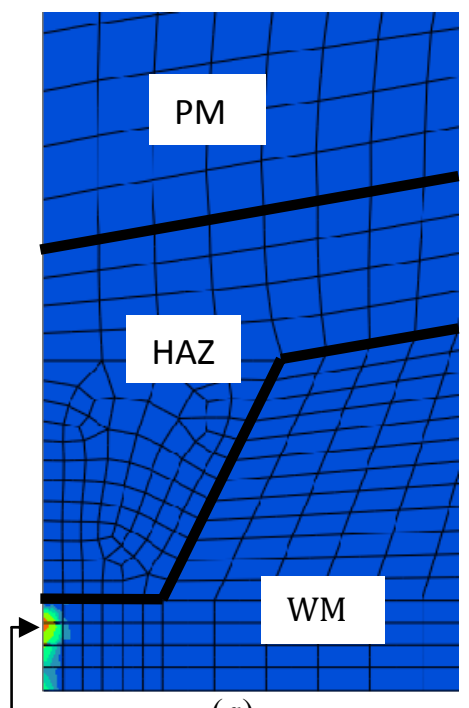

(a)

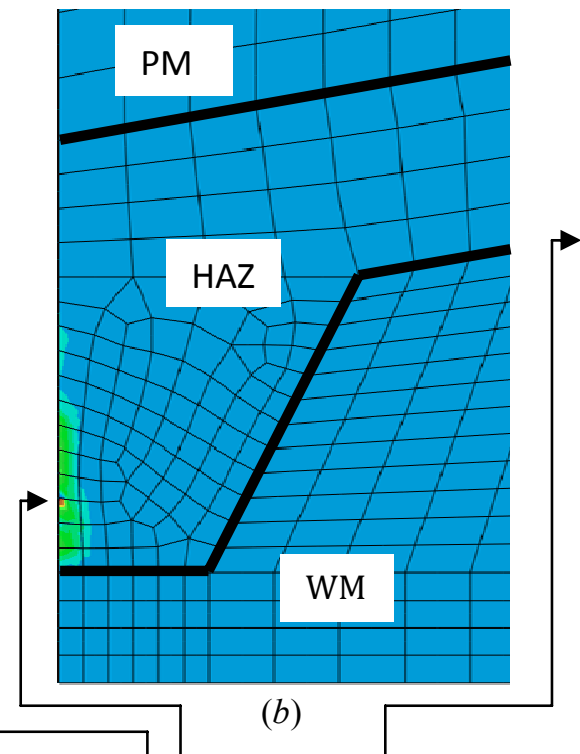

(b)

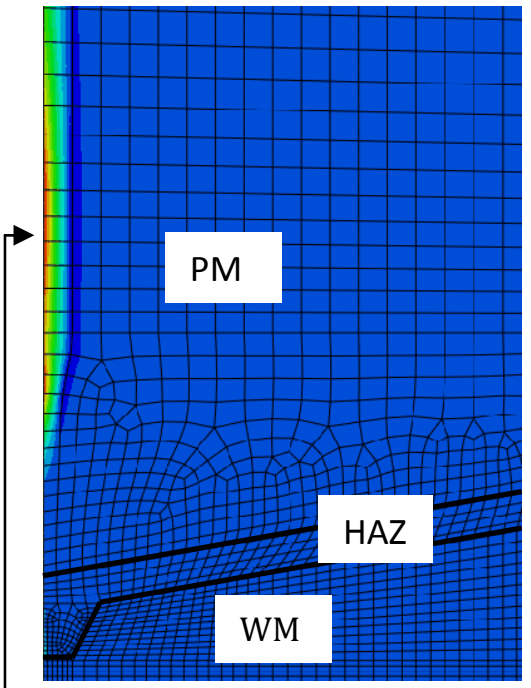

(c)

local reverse plasticity

Fig. 14 Local reverse plasticity failure mechanism of the welded pipe with the yield stress of WM (a)

$$
\sigma_{y}^{W M} / \sigma_{y}^{P M}=0.75, \text { (b) } \sigma_{y}^{W M} / \sigma_{y}^{P M}=1.25 \text { and (C) } \sigma_{y}^{W M} / \sigma_{y}^{P M}=2
$$




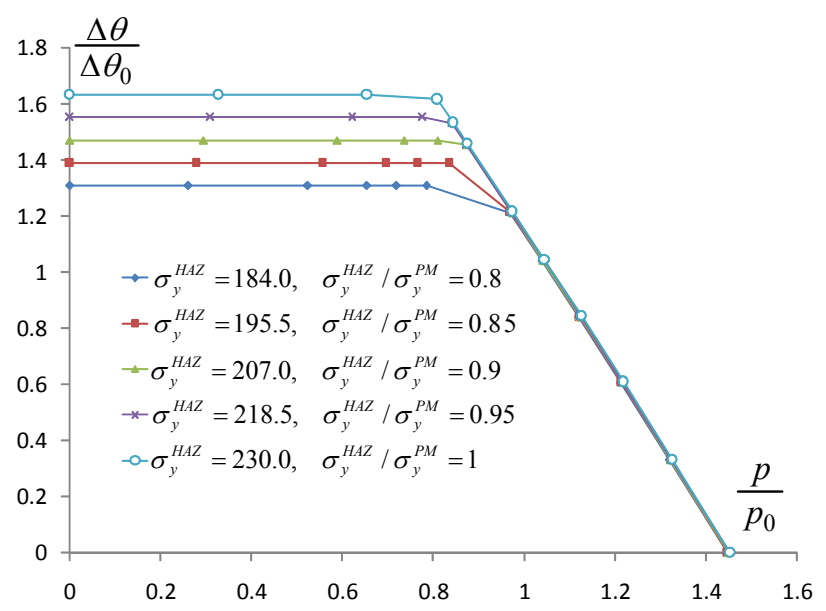

Fig. 15 Shakedown limit interaction curves of the welded pipe with the different yield stress $\sigma_{y}^{H A Z}$, where $\sigma_{y}^{W M}=2 \sigma_{y}^{P M}=460 M P a$

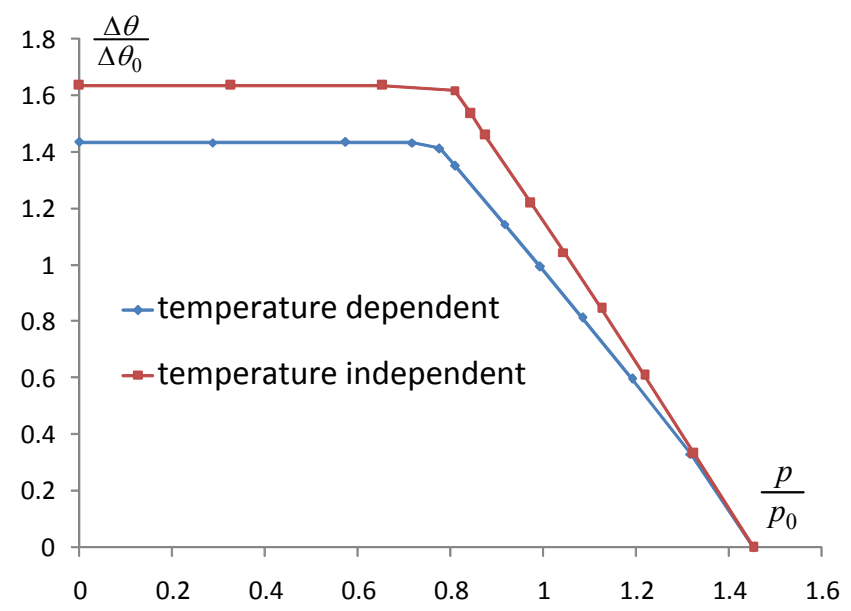

Fig. 16 Shakedown limit interaction curves of the welded pipe with the temperature-dependent yield stress $\sigma_{y}$ 


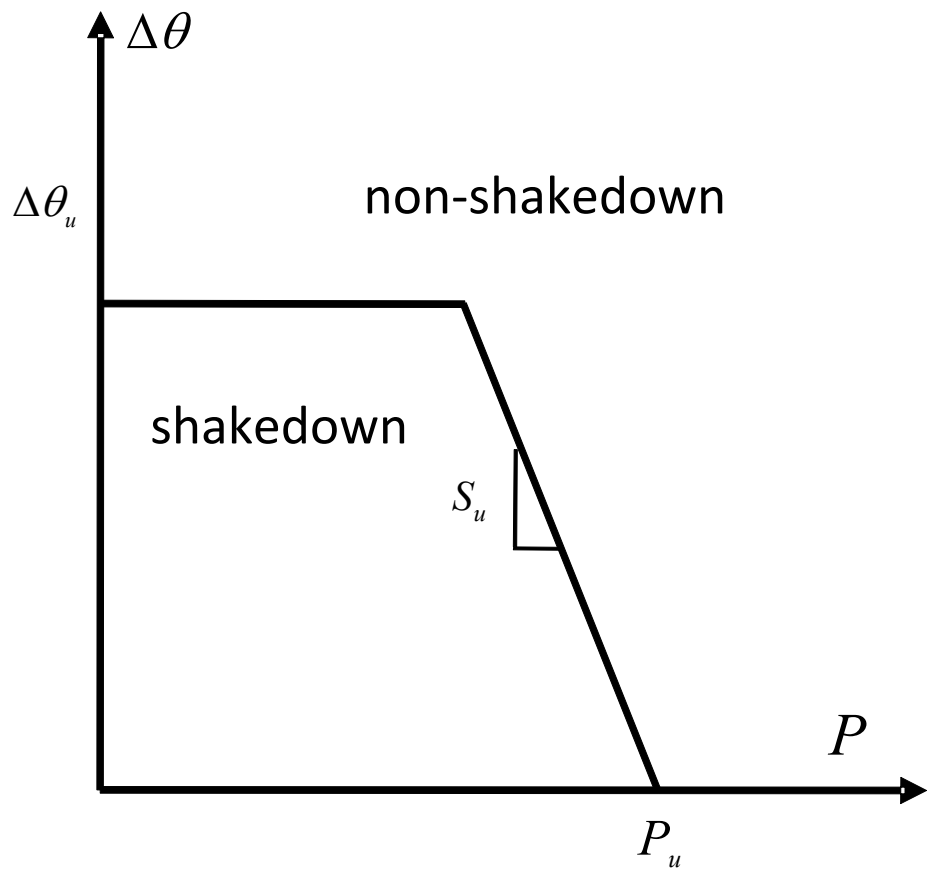

Fig. 17 A shakedown region for the design of welded pipes 

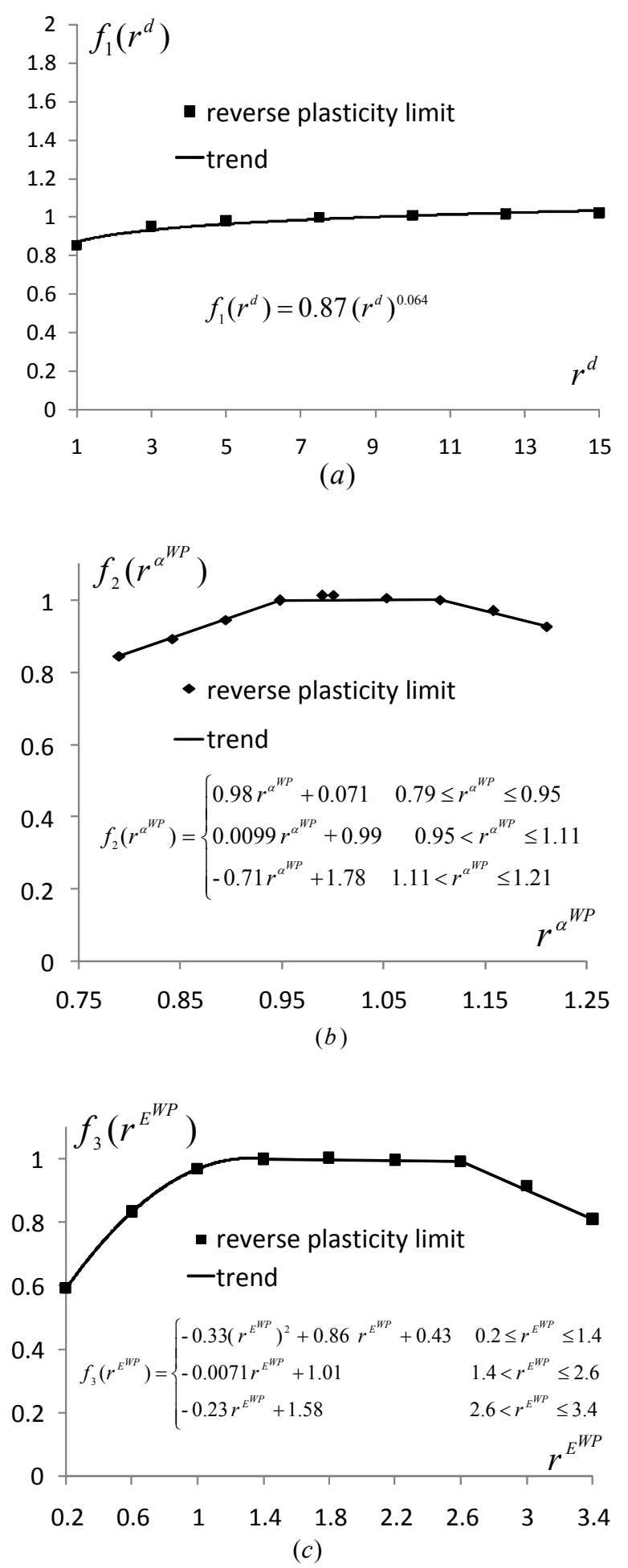

Fig. 18 Influence functions on the reverse plasticity limit with the different ratios (a) $r^{d}=R_{i} / t$, (b)

$$
r^{\alpha^{W P}}=\alpha^{W M} / \alpha^{P M} \text { and (c) } r^{E^{W P}}=E^{W M} / E^{P M}
$$




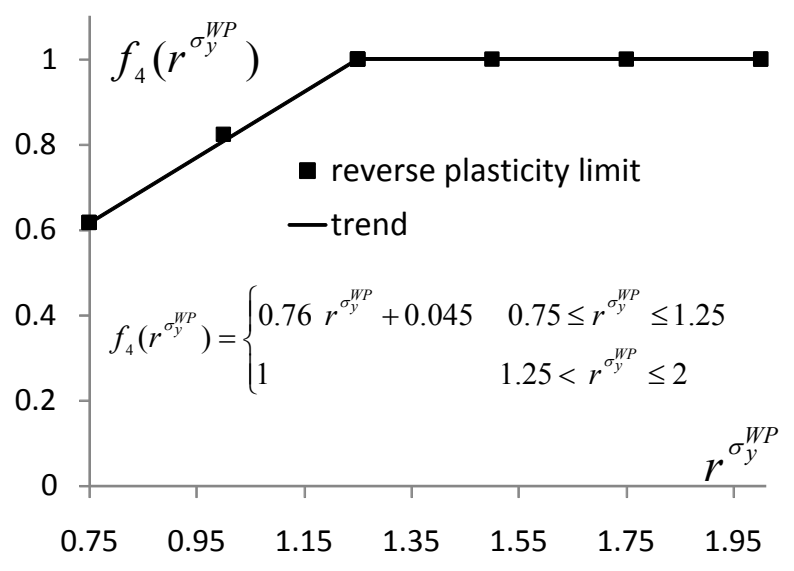

(a)

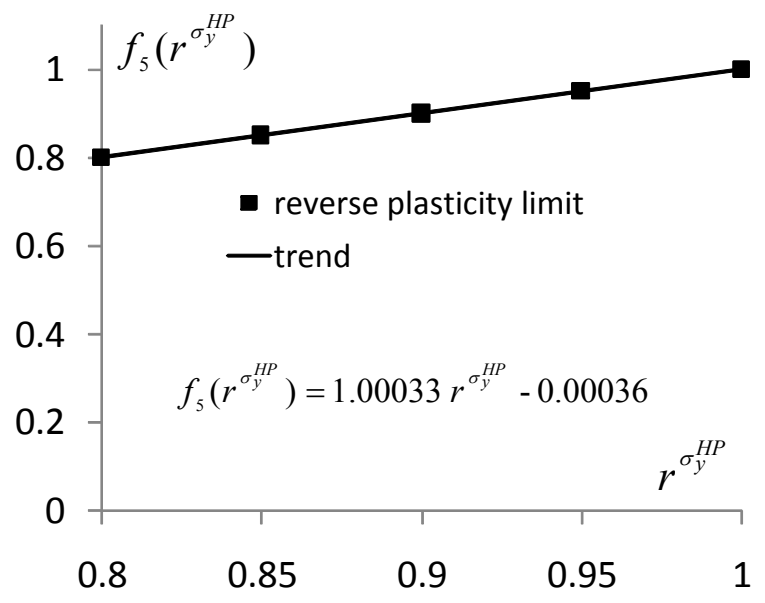

(b)

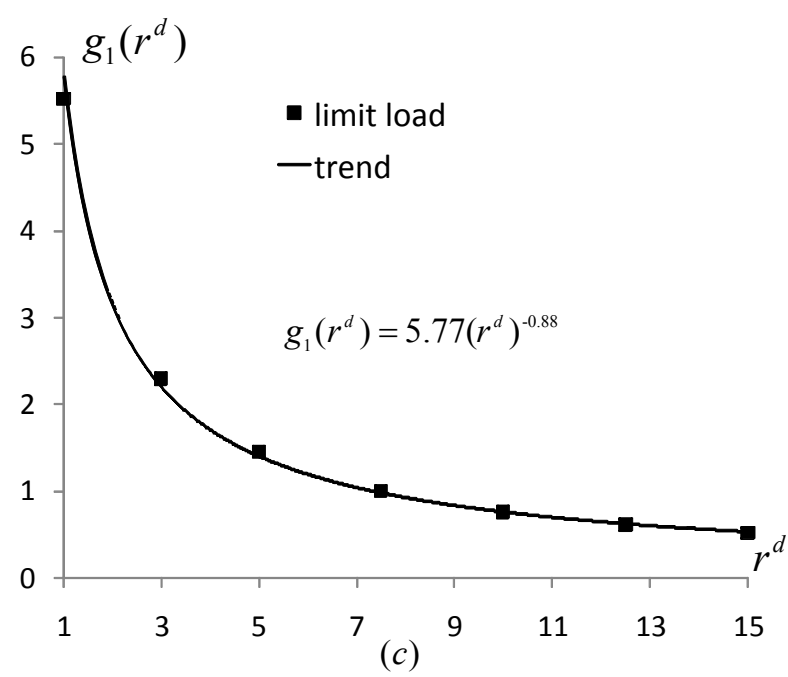

Fig. 19 Influence functions on the reverse plasticity limit with the different ratios (a) $r^{\sigma_{y}^{W P}}=\sigma_{y}^{W M} / \sigma_{y}^{P_{M}}$ and (b) $r^{\sigma_{y}^{H P}}=\sigma_{y}^{H A Z} / \sigma_{y}^{P M}$, and (c) influence function on the limit load with the different ratios

$$
r^{d}=R_{i} / t
$$




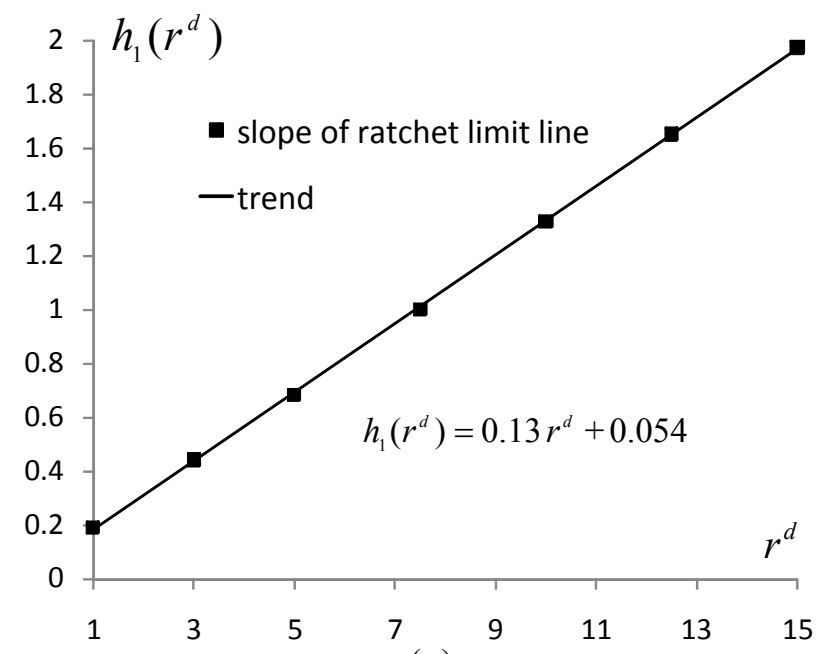

(a)
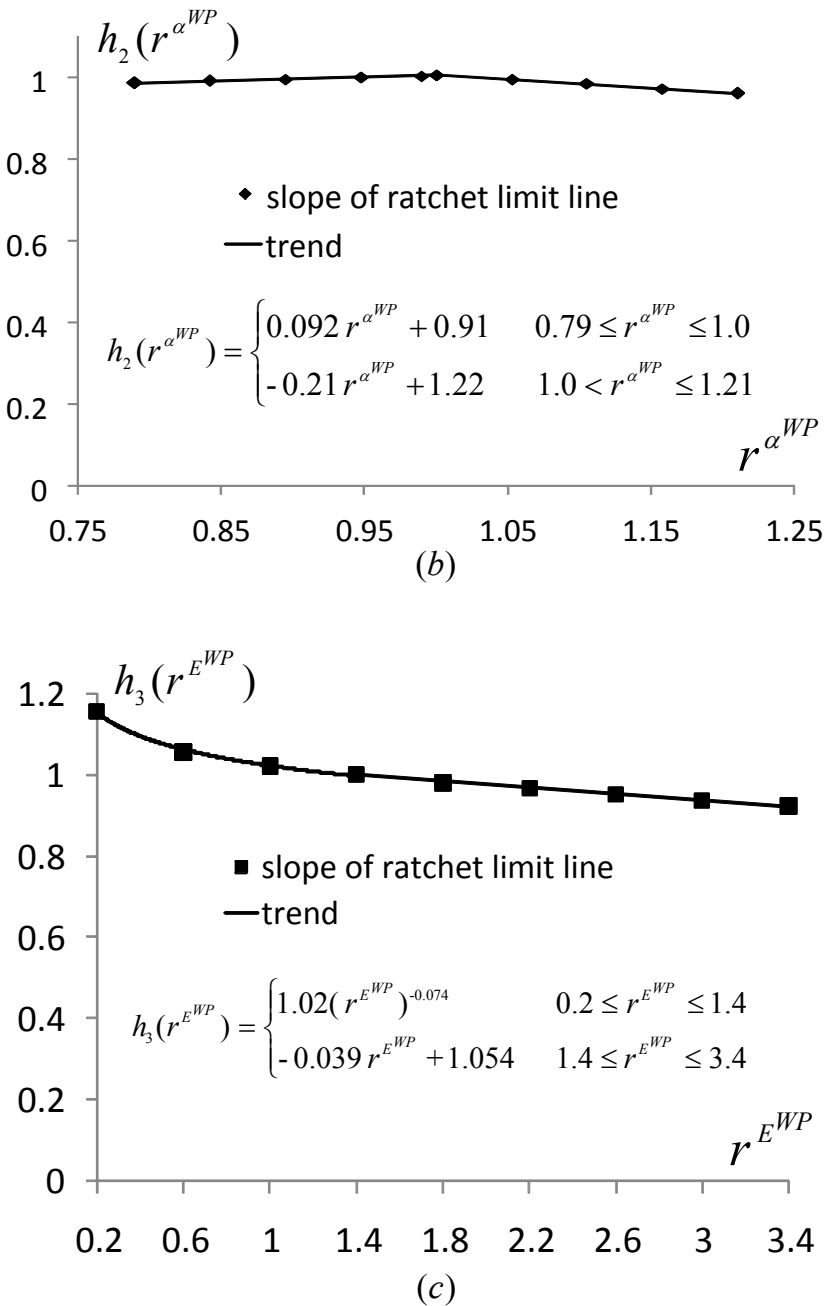

Fig. 20 Influence functions on the slope of the ratchet limit line with the different ratios (a)

$$
r^{d}=R_{i} / t \text {, (b) } r^{\alpha^{W P}}=\alpha^{W M} / \alpha^{P M} \text { and (c) } r^{E^{W P}}=E^{W M} / E^{P M}
$$

